\title{
Sobre a política de combate à pobreza no governo Lula
}

\author{
Rosa Maria Marques ${ }^{1}$ \\ Áquilas Mendes ${ }^{2}$
}

Resumo: O artigo discute o principal programa que integra a política de combate à pobreza desenvolvida pelo governo Lula. Para efeito de comparação, no que diz respeito ao tipo de benefício, às condições de acesso e ao valor transferido, é traçado um perfil do sistema de proteção social construído no Brasil antes da ascensão desse governo ao poder, especialmente em relação à Previdência e a Assistência Social. O artigo aborda, ainda, os principais traços do mercado de trabalho e da distribuição de renda no Brasil, com o intuito de discutir qual pode ser o impacto sobre a renda dos ocupados da implantação do Bolsa Família.

Palavras-chave: política social; política de combate à pobreza; governo Lula; políticas de transferência de renda.

\section{On the policy against poverty in Lula's govermment}

\begin{abstract}
This article discusses the main program within the general policy to fight poverty in Lula's government. It deals with the social security model that has been built in Brazil even before Lula's presidential term, especially in reference to Social and Pension Programs, comparing the kind of benefits provided, the access conditions and the money transfered. It also describes the main characteristics of labor market and income distribution in Brazil, in order to discuss what could be the impact on the income of families targeted by the Bolsa Familia program.
\end{abstract}

Keywords: social policy; anti-poverty policies; Lula's government; income transfers policies.

JEL: I31; I38

\footnotetext{
1 Professora do Programa de Estudos Pós-Graduados em Economia Política da PUCSP. Rua Cayowáa, 560, apt 112. Perdizes. São Paulo. CEP 05018-0oo. E-mail: rosamarques@hipernet.com.br

2 Professor do Departamento de Economia da PUC-SP e da Faculdade de Economia da FAAP/SP, presidente da Associação Brasileira de Economia da Saúde. Rua Pedroso Alvarenga, 401 ap.131. São Paulo. CEP 04531-010. E-mail: aquilasn@uol.com.br
} 
MARQUES, R. \& MENDES, A. Sobre a política de combate à pobreza no governo Lula...

\section{Introdução}

O combate e a erradicação da pobreza no Brasil sempre foram objeto de discussão entre aqueles preocupados com questões como o nível de desigualdade de renda e do patrimônio. Com a eleição do presidente Lula, essa questão, consubstanciada sob a forma do combate à fome e, na prática, desenvolvida como uma transferência de renda, tem sido um dos temas centrais na discussão sobre o sucesso ou não de seu governo.

Por isso o objetivo deste artigo é analisar no que consiste o combate à pobreza desenvolvido pelo presidente Lula e discutir se o Programa Bolsa Família está de acordo ou não com o sistema de proteção que estava sendo construído anteriormente, em especial em relação ao período pós Constituição de 1988. Desse objetivo decorre um segundo, que é analisar até que ponto benefícios presentes na Seguridade Social e o Bolsa Família podem ser tratados como embriões de uma renda garantida ou mínima. Para isso, em primeiro lugar, descreve-se o sistema de proteção social existente no Brasil, pré-existente à ascensão ao poder de Lula e, por isso, fruto de construção de um processo histórico anterior a seu governo, com ênfase na importância do piso previdenciário no resgate da pobreza absoluta e no Benefício de Prestação Continuada, concedido pela Assistência Social. Numa segunda parte, analisa-se o programa carro-chefe do governo na área social, teoricamente desenvolvido para combater a pobreza. A seguir são descritos os principais traços do mercado de trabalho e da distribuição de renda no Brasil com o intuito de eleger um parâmetro para avaliar a importância dos mecanismos de transferência de renda hoje existentes no país. Por último, na parte Reflexões finais, são tiradas algumas conclusões a cerca do que foi apresentado anteriormente e, ao mesmo tempo, avança-se no sentido de propor outros caminhos complementares ao Bolsa Família para que a pobreza de fato comece a ser superada.

\section{A garantia de renda no campo da Seguridade Social ${ }^{3}$}

A discussão sobre a necessidade de uma renda garantida no Brasil está associada ao senador Eduardo Suplicy, defensor incansável dessa proposta. Na Europa, em particular, o debate esteve sempre presente (alguns países há muito já adotavam um tipo de renda mínima), mas foi acirrado pelas condições de precarização do mercado de trabalho a partir de meados dos anos 1970. Esse debate resultou na implantação de

3 A Seguridade Social, segundo o artigo 195 da Constituição brasileira, compreende os ramos Previdência Social, Assistência Social, Sistema Único de Saúde e o seguro-desemprego. 
diferentes variantes de renda mínima, sendo a mais conhecida a Renda Mínima de Insersão (RMI), adotada durante o primeiro governo Mitterand ${ }^{4}$.

No Brasil, muito embora não exista o direito a uma renda mínima, tal como definido na literatura, há aspectos que permitem se evidenciar embriões desse direito, mas imbricado com direitos beneficiários, assistenciais e mesmo a concessões decorrentes de programas. Para analisar esse aspecto peculiar da realidade brasileira no campo das políticas sociais, esta parte do trabalho se debruça sobre a Previdência e a Assistência Social, as quais constituem ramos da Seguridade Social.

\subsection{A renda mínima na Previdência Social}

O movimento político e social contra a ditadura militar - que culmina na democratização do país e na ascensão à presidência da república de José Sarney, em 1985 - teve na discussão e elaboração de uma nova Constituição importante momento, mobilizando as atenções do conjunto da nação. Estava em jogo a definição das bases do novo regime, agora democrático. Entre essas bases, a questão social assumiu importância ímpar, pois se fazia necessário dar passos concretos para resgatar a enorme dívida social herdada do regime anterior. Essa percepção é compartilhada por vários especialistas da área, entre os quais mencionamos Draibe (1989) e Delgado \& Castro (2004).

Entre os vários avanços introduzidos na Constituição de 1988, um dos mais importantes foi o estabelecimento da correspondência entre o piso previdenciário e o salário mínimo, isto é, a definição de que o valor pago a título de aposentadoria não poderia ser menor do que o salário mínimo. Em termos previdenciários, isso seria o equivalente a uma renda de base, tal como existe em sistemas de outros países. Ao ser feito isso, deixou a Previdência Social de ser balizada exclusivamente pelo critério do mérito, isto é, voltada para os trabalhadores que tivessem contribuído ao longo de sua vida ativa. Antes da promulgação da Constituição de 1988, o benefício era calculado com base no valor das contribuições, sendo garantido um mínimo de valor inferior ao do salário mínimo. Depois de instituído o piso de um salário mínimo (que abrangeu inclusive os trabalhadores rurais que não haviam previamente contribuído), dois critérios definidores do acesso aos benefícios previdenciários foram imbricados: o do mérito e o da cidadania.

Dessa forma, paralelamente aos trabalhadores contribuintes com aposentadoria calculada basicamente a partir de suas contribuições,

4 Para maiores esclarecimentos sobre o tema, ver Marques (1997). 
MARQUES, R. \& MENDES, A. Sobre a política de combate à pobreza no governo Lula...

passaram a coexistir os trabalhadores rurais e aqueles com salários muito baixos, que recebem o piso de um salário mínimo, valor pago independentemente da ausência de contribuições ou do fraco esforço contributivo anterior.

O componente "cidadão", agora presente no interior da Previdência Social, nada mais é, então, do que a extrapolação, no campo da proteção social, do mesmo entendimento sobre o que deve ser o valor mínimo pago a um trabalhador ativo: que qualquer salário abaixo dele é considerado imoral pela sociedade ${ }^{5}$.

A importância do piso correspondente ao salário mínimo nos benefícios pagos pela Previdência Social brasileira é claramente evidente quando vemos que, em junho de 2007, a quantidade de benefícios de valor igual a um salário mínimo representou 65,7 do total de benefícios pagos no mês. Desses, 54,2\% foi recebido por trabalhadores urbanos e 45,8 por trabalhadores rurais. Em termos absolutos, foram 16.308 .898 benefícios de valor igual ao salário mínimo. Desnecessário dizer que a imensa maioria desses benefícios se refere a aposentadorias, pois essas constituem $64,6 \%$ do total de benefícios previdenciários pagos pelo Regime Geral. Em termos de volume de recursos envolvidos, foram gastos R\$ 4,5 bilhões, representando 34\% das despesas totais com benefícios realizadas pelo Regime Geral da Previdência Social (MPAS 2007). Evidentemente que a alta concentração da quantidade de benefícios previdenciários de valor igual ao salário mínimo deve-se a dois fatores: ao aumento do valor do salário mínimo promovido durante o governo Lula, embora iniciado na gestão FHC, e no diferencial de reajuste (para menos) aplicado sobe os benefícios que superam esse valor. Ao longo dos anos, portanto, isso está provocando uma concentração dos valores próximos ao piso.

Esses números seriam suficientes para indicar que o piso de um salário mínimo é um poderoso instrumento para a redução da pobreza no Brasil. Mas estudo realizado por técnicos do Ministério da Previdência e Assistência Social (MPAS) verificou que, para o ano de 1999, caso não fossem pagos os benefícios previdenciários, o número de pessoas com renda abaixo da linha de pobreza ${ }^{6}$, passaria de $34 \%$ para $45 \%$ (Brant 2001). Isso significa que em 1999, os benefícios pagos pela Previdência Social eram responsáveis por diminuir em 11 pontos percentuais a população miserável do país.

5 É importante destacar que neste artigo não se discute se o valor do salário mínimo é suficiente ou não para as despesas de um trabalhador, e muito menos de sua família.

$6 \mathrm{Na}$ época que o estudo foi feito, em junho de 2001, a Linha de Pobreza foi definida em R $\$ 98,00$ mensais, conforme metodologia utilizada pelo Instituto de Pesquisas Econômicas Aplicadas. 
O Gráfico 1 apresenta a evolução da pobreza no Brasil no período 1988 1999, considerada ou não a presença dos benefícios previdenciários. Nele fica evidente que, em 1988, portanto antes da vigência do piso de valor igual a um salário mínimo, a Previdência Social era responsável por manter 5,6\% da população acima da linha de pobreza. Em 1999, essa importância já era de $\mathbf{1 1 \%}$. Segundo esse mesmo estudo, somente o aumento dos gastos previdenciários foi responsável por $67 \%$ da redução da população situada abaixo da linha de pobreza, entre 1988 a 1999 (Gráfico 1). ${ }^{7}$

GRÁFICO 1- PREVIDÊNCIA E POBREZA NO BRASIL - 1988-1999 \% DE POBRES

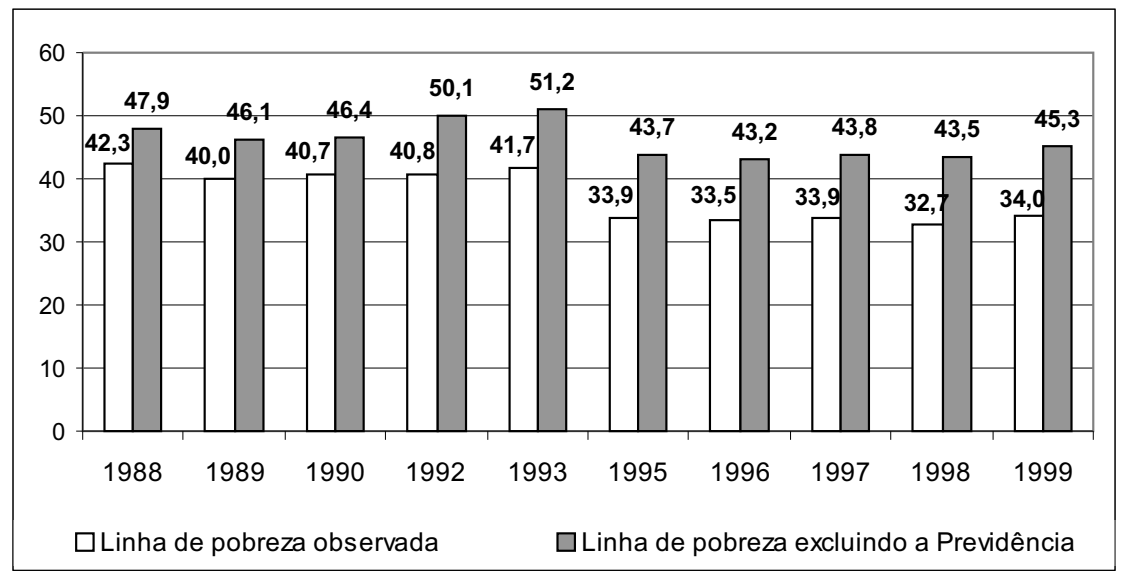

Fonte:PNAD 1992-1999. Não houve PNAD de 1991 a 1994. Elaboração: DISIC/IPEA e SPS/MPAS. Obs: Linha de pobreza $=\mathrm{R} \$$ 98,00. Extraído de Brant (2001).

Beltrão et al (2005) analisaram os efeitos da extensão do direito ao piso aos trabalhadores rurais nas condições de vida dos beneficiários e de suas famílias. Um dos destaques revelados por essa pesquisa é que, no período 1992 a 2002, as famílias de três gerações ou mais invertem a tendência de queda observada nos dez anos anteriores (de 17,5\% passaram a 19,3\% das famílias rurais). Essas famílias são compostas, principalmente, por chefe idoso, filhos e netos, sendo que $57,7 \%$ desses filhos são homens. Segundo esses pesquisadores, "esse padrão de co-residência e suporte intergeracional está associado, entre outras razões, à redução de oportunidades econômicas para a população jovem... (Op.cit: 18)", em outras palavras, ao desemprego. 
GRÁFICO 2- IMPACTO DO AUMENTO DOS GASTOS DA PREVIDÊNCIA SOBRE O NÍVEL DE POBREZA NO BRASIL - 1988-1999 (\% DE POBRES)

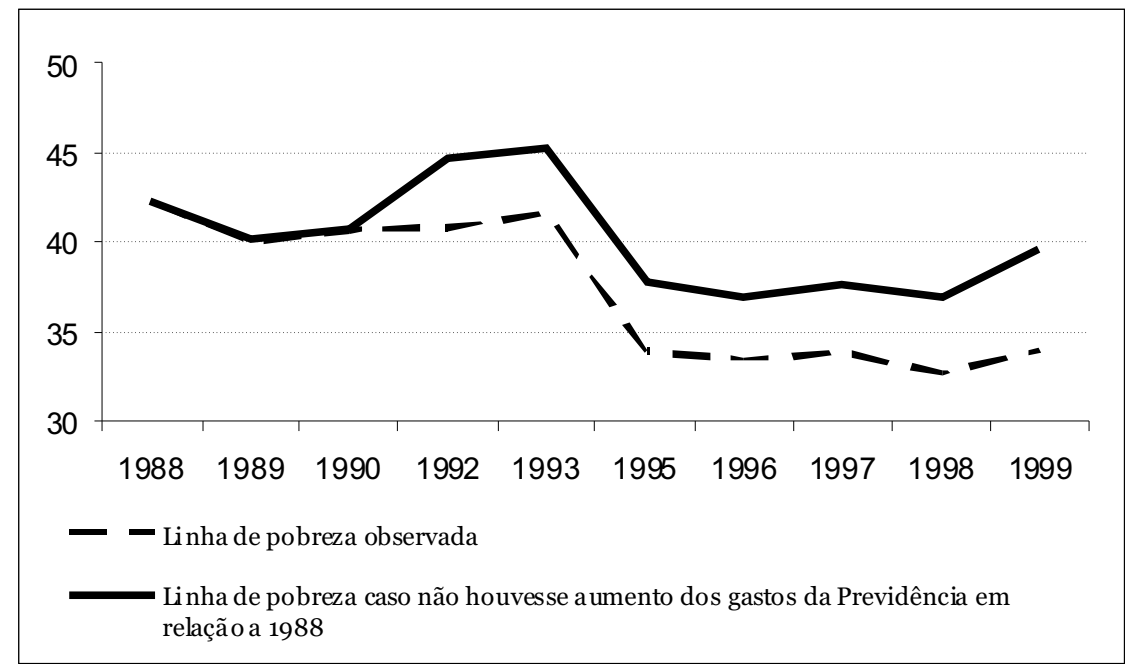

Fonte: Brant (2001).

Essa pesquisa também indica que a ampliação da cobertura junto aos rurais contribuiu em muito para a redução da pobreza rural. Seguem as evidências dessa realidade:

Desde 1982, a maior proporção de famílias pobres e indigentes ${ }^{8}$ era encontrada entre as famílias sem idosos . Entre 1989 e 1992, essas proporções declinaram nos dois tipos de famílias que continham idosos e aumentaram naquelas sem idosos. Dessa forma, as famílias de idosos continuaram a ser as menos pobres, aumentando o hiato com a situação de pobreza das famílias sem idosos. Nos anos 1990, a pobreza e a indigência declinaram em todos os tipos de famílias, com uma redução mais intensa nas famílias de idosos, ampliando ainda mais o hiato existente desde 1982. (Beltrão et al 2005:18)(Tabela 1)

Em março de 2006, o MPS divulgou pesquisa que versa sobre a Evolução Recente da Proteção Social e seus Impactos sobre o Nível de Pobreza. Esses resultados, fundados na Pesquisa Nacional por Amostra de Domicílios - PNAD 2004 indicam que a Previdência Social promove impacto significativo sobre o nível de pobreza da população brasileira.

8 Os pesquisadores do IPEA explicam, em seu texto que "Denominamos pobres as famílias com renda familiar per capita abaixo de um certo valor e, de indigentes, as famílias com renda menor do que a metade desse valor. O valor foi calculado para cada um dos anos estudados por Ricardo Paes de Barros para zonas urbanas e rurais das cinco grandes regiões brasileiras"(Op. cit: 10) Para definir esses valores Barros et al 2000: 10 definiu que "a linha de indigência, endogenamente construída, referese somente à estrutura de custos de uma cesta alimentar, regionalmente definida, que contemple as necessidades de consumo calórico mínimo de um indivíduo. A linha de pobreza é calculada como múltiplo da linha de indigência, considerando os gastos com alimentação como uma parte dos gastos totais mínimos, referentes, entre outros, a vestuário, habitação e transportes". 
MARQUES, R. \& MENDES, A. Sobre a política de combate à pobreza no governo Lula...

TABELA 1- BRASIL RURAL: FAMÍLIAS SEGUNDO A CONDIÇÃO DE POBREZA POR TIPO - 1982, 1992 E 2002

\begin{tabular}{lccc|ccc|ccc}
\hline Tipo de Família & \multicolumn{3}{c|}{1982} & \multicolumn{3}{c|}{1992} & \multicolumn{3}{c}{2002} \\
\cline { 2 - 10 } & Indigente & Pobre* $^{*}$ & Não Pobre & Indigente & Pobre* & Não Pobre & Indigente & Pobre $^{*}$ & Não Pobre \\
\hline Sem idosos & 35,8 & 30,1 & 34,1 & 43,7 & 27,1 & 29,2 & 33,6 & 28,7 & 37,7 \\
De idosos & 18,7 & 33,5 & 47,8 & 17,2 & 28,2 & 54,5 & 6,9 & 20,9 & 72,2 \\
Comidosos & 23,0 & 37,5 & 39,5 & 22,0 & 33,5 & 44,5 & 12,4 & 33,0 & 54,6 \\
Total & 31,9 & 31,1 & 37,1 & 36,5 & 27,6 & 35,9 & 26,1 & 26,8 & 47,0 \\
\hline
\end{tabular}

Fonte: IBGE/PNAD de 1982, 1992 e 2002

${ }^{*}$ Pobre, mas não indigente.

Segundo a PNAD, considerando que um rendimento familiar inferior a meio salário mínimo per capita definiria a condição de pobreza de uma pessoa, haveria, em 2004, 52,45 milhões de pessoas nessa situação, levando-se em conta todas as fontes de rendimento. Se desses rendimentos fossem deduzidos os benefícios previdenciários, o contingente de pobres assim definidos passaria para 72,63 milhões. Em outras palavras, nesse ano, a Previdência Social foi responsável por retirar da situação de pobreza 20,17 milhões de pessoas. (MPS 2006).

Esse conjunto de informações mostra que os constituintes introduziram dispositivos/direitos no corpo da Previdência Social que tiveram grande impacto sobre o nível de pobreza no país. Destaca-se, mais uma vez, que se tratou de uma constituinte pós-ditadura militar, mas com claro domínio de representantes de partidos burgueses.

\section{2 A garantia da renda mínima no campo da Assistência Social}

Para aqueles que não contribuíram à Previdência Social, que não são trabalhadores rurais e que integram família de baixa renda, o sistema de proteção social brasileiro prevê, ainda, o pagamento de um benefício, também de valor igual ao salário mínimo, no campo da Assistência Social. Esse benefício, embora tenha sido regulamentado depois da promulgação da Constituição de $1988^{9}$, nela foi definido. Nesse caso o risco velhice $^{10}$ toma o nome de Benefício de Prestação Continuada (BPC) e é concedido a pessoas com 65 anos ou mais ${ }^{11}$, que apresentam renda média mensal familiar inferior a $25 \%$ do salário mínimo vigente.

9 O Benefício de Prestação Continuada (BPC) é definido pela Lei 8.742, de 7 de dezembro de 1993, Lei Orgânica da Assistência Social (LOAS).

$10 \mathrm{Na}$ literatura relativa às políticas sociais e no direito previdenciário, o termo risco velhice refere-se à inexorável perda de capacidade de trabalho e, portanto, de renda, que advém com a idade avançada. Esse risco, de caráter previsível, é coberto pelo direito à aposentadoria, pensão ou renda garantida (os nomes variam conforme o país). Os riscos mais tradicionais que os sistemas de proteção social cobrem são: doença, velhice, invalidez, morte e desemprego.

$11 \mathrm{O}$ BPC também é concedido à pessoa portadora de deficiência, quando essa lhe impede de ter vida independente e trabalhar. 
Essa última condição é considerada baixa entre os especialistas da área, mais rígidas do que as exigidas para a concessão de um salário mínimo aos trabalhadores rurais, deixando de proteger segmento importante da população idosa, que também não conta com a cobertura da Previdência Social ${ }^{12}$. Os trabalhadores rurais, para terem acesso ao piso de um salário mínimo, apenas necessitam comprovar que trabalharam durante o período definido na legislação e, evidentemente, terem atingido a idade mínima para a aposentadoria.

O Benefício de Prestação Continuada beneficiou, em março de 2007, 2.511.399 pessoas, a um custo de R $\$ 881$ milhões no mês. Em outubro de 2006, foram pagos 2.445.602 benefícios de prestação continuada no país ${ }^{13}$. Desses, 1.278.877 foram destinados a pessoas portadores de deficiência e 1.166.725 a idosos de baixa renda. A distribuição entre as regiões do país é mostrada nos Gráficos 3 e 4. As regiões que mais participam na distribuição dos benefícios de prestação continuada para pessoas portadoras de deficiência são o Nordeste $(39,6 \%)$ e a Região Sudeste $(30,4 \%)$. No caso do BPC para os idosos, essa situação se inverte: Sudeste $(38,9 \%)$ e Nordeste $(31,8 \%)$.

GRÁFICO 3- DISTRIBUIÇÃO DO BPC - PESSOAS PORTADORAS DE DEFICIÊNCIA, POR REGIÃO - OUTUBRO DE 2006

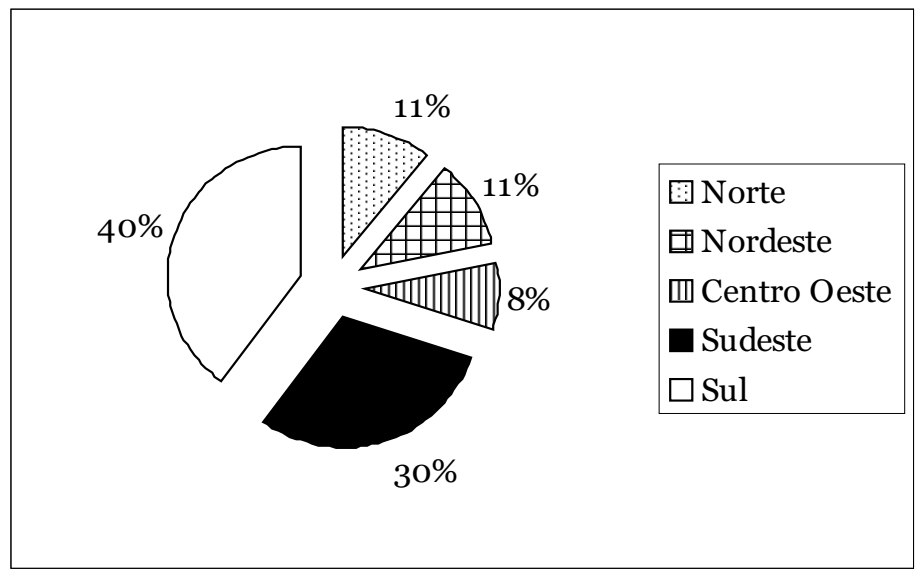

Fonte: Marques et al (2006).

12 Em 2001, de acordo com o Instituto Brasileiro de Geografia e Economia (IBGE), 40,7 milhões de ocupados junto ao setor privado da economia não eram contribuintes do Regime Geral da Previdência social ou a qualquer tipo de outro regime, correspondendo a $57,7 \%$ da população ocupada nesse setor, nesse ano. Esse contingente integra o chamado mercado informal da economia brasileira.

13 É utilizado o dado de outubro de 2006 porque essa era a última informação disponível quando foi realizada uma pesquisa sobre o universo dos beneficiários (Marques et al 2006). $O$ uso de um mês não interfere estatisticamente, pois a série do BPC não apresenta sazonalidade. 

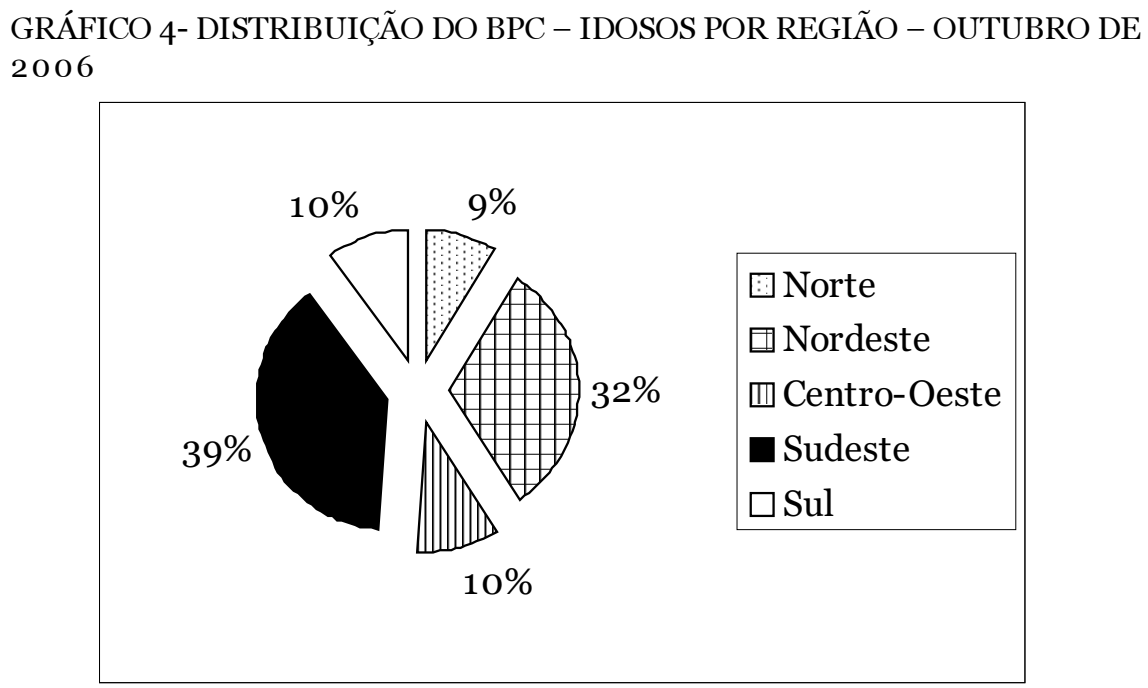

Fonte: Marques et al (2006).

Na comparação com o total das transferências constitucionais aos municípios, os recursos envolvidos com o BPC (pessoas portadoras de deficiência e idosos) variam entre 27,13\% (Região Centro-Oeste) a 12,46\% (Região Sul) ${ }^{14}$. Na Região Norte, esse percentual vai de 27,01\% (Amapá) a 9,79\% (Roraima). No Nordeste, o maior percentual encontrado foi o

de Pernambuco (30,29\%) e o menor o de Piauí (11,05\%). Nos estados da Região Centro-Oeste, a participação dos recursos do BPC em relação às transferências constitucionais é muito homogênea. Já na Região Sudeste, Rio de Janeiro registra um percentual de 20,76\% e o Espírito Santo 13,29\%. Na Região Sul, cujos estados são os que, em conjunto, registram os menores percentuais, assim mesmo destaca-se a situação de Santa Catarina, com apenas $7,33 \%$.

A análise das capitais demonstra que, em geral, a importância do BPC em relação às transferências constitucionais nelas é maior do que no estado, com exceção de Palmas e Vitória. Esse resultado está de acordo com o esperado, pois de um lado as capitais recebem relativamente menos do FPM e, de outro, não se coloca para os trabalhadores sem vinculo empregatício a possibilidade de se aposentarem pelo regime especial dos rurais, muito embora precisem passar pelo teste de meios.

No caso de Palmas, certamente a baixa taxa de participação dos recursos do BPC $(5,95 \%)$ se deve ao fluxo migratório recebido pelo município nos últimos anos, alterando o volume de recursos recebidos a título de

14 Os dados do BPC aqui mencionados foram extraídos de (Marques et al 2006). 
transferências constitucionais. No geral, o leque da variação observada nas capitais vai de 79,44\% (Recife) a 5,95\% (Palmas).

Com relação às transferências do FPM, o maior percentual é observado na Região Centro-Oeste (44,41\%) e o menor na Região Sul $(19,82 \%)$. Entre os estados, o destaque fica com o Rio de Janeiro $(65,18 \%)$, provavelmente influenciado por sua capital, onde há alta participação de idosos. O menor percentual é encontrado em Roraima, com 12, 51\%. Na comparação das capitais com os resultados encontrados para os estados, há uma tendência clara: nas capitais, a importância dos recursos do BPC em relação às transferências do FPM é maior do que a observado nos estados. As exceções ficam por conta de: Roraima (levemente mais baixo), Tocantins e Espírito Santo. Chama atenção o peso do BPC em Recife, Campo Grande, Rio de Janeiro e São Paulo, onde os recursos do BPC ultrapassam as transferências do FPM. No caso do Rio de Janeiro é 2,2 vezes maior e, em São Paulo, 5,4 vezes (Op. cit). Essa é a realidade para diferentes tipos de municípios localizados na região nordeste, reconhecidamente a mais pobre do Brasil, mas também se reproduz, com menor impacto, mesmo nas regiões sudeste e sul, onde o nível de pobreza é mais reduzido.

É importante salientar que o BPC, embora esteja no campo da Assistência Social, pois exige teste de meios, constitui um direito, o que o diferencia em relação a outras políticas chamadas de assistenciais.

\section{Fome Zero - Bolsa Família}

De acordo com o Projeto Fome Zero: uma Proposta de Segurança Alimentar para o Brasil, a população com renda abaixo da linha de pobre$\mathrm{za}^{15}$, que seria objeto de sua atenção prioritária, correspondia a 44,043 milhões de pessoas, envolvendo 9,32 milhões de famílias. Em outras palavras, o tamanho da pobreza absoluta se referia a $27,8 \%$ da população total do país; a 19,1\% da população das regiões metropolitanas, a $25,5 \%$ das áreas urbanas não-metropolitanas e a 46,1\% da população rural. Em relação às famílias, correspondia a $21,9 \%$ das famílias brasileiras. Mas segundo outra metodologia de cálculo, o tamanho da pobreza é ainda maior, atingindo 57,7 milhões de pessoas (IBRE, 2001) ${ }^{16}$. Embora a diferença diga respeito a milhões de pessoas, destaca-se que, indepen-

\footnotetext{
15 Para esse cálculo, a equipe de Lula utilizou o critério de linha de pobreza do Banco Mundial (U\$ 1,o8 por dia), ajustando para os diferentes níveis regionais de custo de vida e pela existência ou não de autoconsumo. A pobreza absoluta considera um mínimo para a sobrevivência; a pobreza relativa, como o nome diz, tem como referência o padrão de vida de uns em relação a outros.

16 Esse Instituto trabalhou com o critério de $\mathrm{R} \$ 60,00$ per capita mensal como definidor da linha de pobreza.
} 
dentemente do número adotado, a pobreza absoluta no Brasil atinge parcela extremamente significativa de sua população. O tamanho dessa pobreza torna problemática, inclusive, a utilização do termo "focalizado" para as políticas dirigidas a essa população. É claro que no sentido restrito não se tratam de políticas universais, mas o tamanho da população-alvo é "desmesurado".

Mesmo antes de seu início, especialistas da área social criticaram duramente determinados aspectos do Projeto Fome Zero, especialmente com relação às idéias relacionadas ao Cartão, instrumento da transferência de renda que seria destinada às famílias em situação de extrema pobreza. Na sua concepção original, o Cartão somente poderia ser utilizado para compra de alimentos, e estes seriam previamente definidos pelo governo. É claro que essa definição não seria gratuita, estando vinculada à preocupação de desenvolver certas culturas locais, entre outros aspectos. De qualquer forma, a determinação de que a renda recebida deveria ser gasta somente em alimentação indicava desconhecimento com relação ao comportamento das famílias mais pobres. Como é sabido, empiricamente, pessoas vivendo abaixo da linha de pobreza dirigem praticamente todo o acréscimo de renda para a compra de alimentos. Mas existem pesquisas que comprovam esse conhecimento "popular". Para se ter uma idéia, estudo sobre o impacto de outros programas de transferência de renda mostrou que, para famílias com renda mensal per capita inferior a $\mathrm{R} \$ 90,00$, para cada 1 real $(\mathrm{R} \$ 1,00)$ de benefício recebido, 89 centavos são gastos em alimentos (MINISTÉRIO DA SAÚDE 2003). Além disso, o dirigismo da compra pareceu, apesar de suas boas intenções, estar fundado na idéia de que o povo pobre não sabe comprar, sendo de um autoritarismo a toda prova.

Passados alguns meses, durante os quais seu principal representante foi objeto de constantes críticas com relação ao Fome Zero, o que levou a seu afastamento, o programa ficou basicamente concentrado no chamado Programa Bolsa Família, muito embora a "marca" Fome Zero continue a fazer parte dos sites do governo e, em seu site específico estejam arroladas atividades desenvolvidas por diferentes ministérios, tais como incentivo à agricultura familiar, o Plano Nacional de Reforma Agrária, entre vários outros.

Segundo os órgãos oficiais do governo, o Bolsa Família foi criado para atender duas finalidades básicas: enfrentar o maior desafio da sociedade brasileira, que é o de combater a miséria e a exclusão social, e também promover a emancipação das famílias mais pobres. Antes de sua criação pelo governo Lula, havia vários programas voltados à família de renda abaixo da linha de pobreza, tal como o Bolsa Escola, Bolsa Alimentação, Cartão Alimentação e o Auxílio Gás. A unificação de todos esses programas deu origem ao Bolsa Família. 
MARQUES, R. \& MENDES, A. Sobre a política de combate à pobreza no governo Lula...

O Bolsa Família, ao contrário do piso previdenciário e do BPC, não constitui um direito. Como seu nome designa, trata-se de um programa, fruto de decisão do executivo federal. Enquanto o programa estiver sendo implementado, as famílias enquadradas em seus critérios de acesso têm "direito" àquilo que o programa concede. Contudo, do ponto de vista das políticas sociais, isso não constitui um direito, pois programas podem ser criados ou extintos sem que a sociedade discuta. O Bolsa Família é o principal programa de transferência de renda existente no país e aquele que atinge o maior número de pessoas. Em outubro de $2006^{17}$, este programa alcançava 11.009 .341 famílias, ao custo de R\$ 680,08 milhões no mês. Em termos de população, isso significou uma cobertura de 48.441.100 pessoas, isto é, $25,9 \%$ da população estimativa pelo IBGE para 2006. Em relação à meta do governo para o ano, isso equivale a $98,2 \%$.

Em termos de distribuição entre as regiões, as famílias beneficiárias do Bolsa Família estão altamente concentradas nas regiões Nordeste $(49,8 \%)$ e Sudeste $(26,07 \%)$. Considerando o valor médio repassado por família beneficiária em outubro de 2006, para o Brasil como um todo, de R $\$ 61,77$, verifica-se que ele varia entre as regiões geográficas do país, sendo R\$ 67,60 na Região Norte, R\$ 65,36 no Nordeste, R\$ 56,66 no Sudeste, R\$ 55,55 no Sul e R\$ 54,93 no Centro-Oeste.

Os repasses do Bolsa Família aos municípios equivalem, no período de janeiro a outubro de 2006, a 15,0\% das transferências constitucionais federais efetuadas aos municípios. Na Região Nordeste, esse percentual é ainda maior (23,5\%). Nas demais regiões, com exceção do Norte, onde é praticamente igual à média nacional, é bastante inferior.

No Nordeste, os estados do Pernambuco, Ceará, e Maranhão registram um percentual acima da média da região, $25,5 \%, 25,7 \%$ e $25,7 \%$. No Norte (16\%), o destaque fica por conta do Amapá, registrando apenas 7,9\%. Na Região Centro-Oeste (10,5\%), os percentuais dos estados são muito homogêneos, próximos da média regional. Na Região Sudeste $(10,4 \%)$, o percentual varia entre $13,5 \%$ (Minas Gerais) e 8,3\% (São Paulo). Na Região Sul $(8,4 \%)$, apenas Santa Catarina se destaca, com um percentual inferior à média regional $(5,2 \%)$.

Esses indicadores do Bolsa Família - em relação ao total da população e da Renda Disponível dos municípios brasileiros - mostram quão importantes são os programas compensatórios na promoção da distribuição da renda e da atividade econômica nos recantos mais pobres do país. Persiste, no entanto, o fato de seus benefícios não derivarem de um

17 Da mesma forma que para o BPC, o benefício do Bolsa Família não apresenta sazonalidade. Esse mês aqui serve de referência porque era o último dado disponível quando a pesquisa já citada foi realizada. 
direito, de forma que esses podem ser extintos pelo simples ato de vontade do governo federal de plantão (idem, ibidem). O Quadro 1 apresenta a definição do público-alvo e o valor pago pelo Bolsa Família no momento em que a pesquisa supra citada foi realizada.

No início de 2007 , o valor variável foi elevado para $R \$ 18$,oo e o valor Básico, sem condicionalidade, para R $\$ 58,00$. Dessa forma, o valor recebido pela família pode variar entre $\mathrm{R} \$ 18$, oo a $\mathrm{R} \$ 118,00$.

\section{Mercado de Trabalho e Distribuição de Renda}

Para podermos avaliar a dimensão da política de combate à pobreza realizada nos dois primeiros anos do governo Lula, é preciso se ter uma idéia de como se estrutura o mercado de trabalho no Brasil e de como é distribuída a renda nacional. Portanto, embora não seja objetivo central deste artigo, alguns aspectos do mercado de trabalho auxiliam na avaliação do Bolsa Família. Mais adiante, na parte chamada de reflexões finais, fica acentuada a comparação com aspectos do mercado de trabalho brasileiro, tanto no que se refere às rendas utilizadas como critério de acesso ao Bolsa Família, como em relação aos valores pagos a seus beneficiários.

QUADRO 1- PÚBLICO-ALVO DO PROGRAMA BOLSA FAMÍlIA E SEU BENEFÍCIO

\begin{tabular}{|c|c|c|c|c|}
\hline \multicolumn{2}{|c|}{ Critério de Elegibilidade } & \multirow{2}{*}{$\begin{array}{l}\text { Ocorrência de crianças } \\
\text { / adolescentes 0-15 } \\
\text { anos, gestantes e } \\
\text { nutrizes }\end{array}$} & \multirow{2}{*}{$\begin{array}{l}\text { Quantidade e } \\
\text { Tipo de } \\
\text { Benefícios }\end{array}$} & \multirow{2}{*}{$\begin{array}{l}\text { Valores } \\
\mathrm{R} \$\end{array}$} \\
\hline $\begin{array}{l}\text { Situação das } \\
\text { Famílias }\end{array}$ & $\begin{array}{l}\text { Renda Mensal } \\
\text { per capita }\end{array}$ & & & \\
\hline \multirow{3}{*}{$\begin{array}{l}\text { Situação de } \\
\text { Pobreza }\end{array}$} & \multirow{3}{*}{$\begin{array}{l}\text { De } R \$ 60,01 \text { a } \\
R \$ 120,00\end{array}$} & 1 Membro & (1) Variável & 15,00 \\
\hline & & 2 Membros & (2) Variável & 30,00 \\
\hline & & $3 \mathrm{ou}+$ Membros & (3) Variável & 45,00 \\
\hline \multirow{4}{*}{$\begin{array}{l}\text { Situação de } \\
\text { Extrema } \\
\text { Pobreza }\end{array}$} & \multirow{4}{*}{ Até $\mathrm{R} \$ 60,00$} & Sem ocorrência & Básico & 50,00 \\
\hline & & 1 Membro & $\begin{array}{l}\text { Básico + (1) } \\
\text { Variável }\end{array}$ & 65,00 \\
\hline & & 2 Membros & $\begin{array}{l}\text { Básico + (2) } \\
\text { Variável }\end{array}$ & 80,00 \\
\hline & & $3 \mathrm{ou}+$ Membros & $\begin{array}{l}\text { Básico + (3) } \\
\text { Variável }\end{array}$ & 95,00 \\
\hline
\end{tabular}

Fonte: Ministério do Desenvolvimento Social e Combate a Fome 
Os trabalhadores brasileiros enfrentam uma realidade extremamente adversa. O primeiro deles é, sem dúvida o desemprego. Em dezembro de 2006, quando a economia acumulou um crescimento anual de 3,7\%, na Região Metropolitana de São Paulo (principal centro das atividades no país) a taxa de desemprego aberto estava em $9 \%$, isto é, 3,2 pontos percentuais acima do observado em dezembro de 1985. Levando-se em conta o desemprego oculto (trabalho precário e desemprego por desalento), a taxa atingiu 14,2\%, quando em dezembro de 1985 estava em 9,8\%. Assim, mesmo tendo o desemprego baixado em relação ao ano de 2003 (primeiro ano do governo Lula), a falta de trabalho nas últimas décadas constitui uma realidade persistente e em alta, situação que se reproduz em todos os cantos do país.

O segundo grande problema se refere ao nível de formalização daqueles que têm a sorte de ainda contarem com um trabalho. Em 2005, de acordo com PNAD, e considerando os ocupados com 10 anos ou mais, $18,7 \%$ dos trabalhadores assalariados agrícolas, 32,2\% dos trabalhadores não agrícolas e 73,8\% dos trabalhadores domésticos não tinham carteira assinada. Em termos de contribuição para algum instituto de previdência (pública ou privada), a pesquisa identificou somente $47,4 \%$ da população ocupada. Além disso, significar que esse contingente está excluído da cobertura para o momento da aposentadoria implica não estar regido pelos dispositivos legais que regem a relação capital / trabalho, não tendo direito, por exemplo, a férias remuneradas e ao $13^{\circ}$ salário, quando forem trabalhadores assalariados ou mesmo trabalhadores domésticos. Esses são os trabalhadores que pertencem ao chamado mercado informal. Em geral são assalariados sem carteira assinada acesso aos direitos decorrentes das leis trabalhistas) aqueles que exercem atividades por "conta própria" (o que pode representar desde alguém que vende mercadorias nas ruas a eletricistas, chaveiros e mesmo pessoas especializadas com título universitário) e os trabalhadores domésticos.

A terceira grande dificuldade que enfrenta o trabalhador brasileiro é o nível de sua renda. A grande maioria dos ocupados ganha até três salários mínimos (ou nada recebe), tal como pode ser visto na Tabela 3. Em 2006, esse segmento de trabalhadores representou 68,33\% do total apurado pela PNAD; se a eles se somam os sem rendimentos, esse percentual sobe para $81,49 \%$. Mas, paralelamente a isso, é digno de nota que essa tabela também registra uma tendência à queda da participação relativa dos sem rendimentos. É possível que a implantação do Programa Bolsa Família tenha contribuído para essa redução.

Os documentos analíticos da PNAD de 2005 e 2006, em Síntese dos (documento que concretiza seu vínculo à cobertura previdenciária e o Indicadores, que estão disponíveis no site do IBGE, salientam que o rendimento médio ficou estável nos anos 2003 e 2004, mas que esse 
apresentou ganho real em 2005. Assim mesmo, comparado a 1996, esse rendimento foi $15,1 \%$ menor $^{18}$. Em 2006, o rendimento médio aumentou 7,5\% em relação a 2005; expansão atribuída ao aumento do salário mínimo (13,3\% em relação a 2005).

TABELA 3- DISTRIBUIÇÃO PESSOAS DE 10 ANOS OU MAIS DE IDADE, ECONOMICAMENTE ATIVAS NA SEMANA DE REFERÊNCIA, POR CLASSE DE RENDIMENTO MENSAL - BRASIL

\begin{tabular}{lcccc}
\hline Faixas SM & $\mathbf{2 0 0 3}$ & $\mathbf{2 0 0 4}$ & $\mathbf{2 0 0 5}$ & $\mathbf{2 0 0 6}$ \\
\hline Até 1/2 SM & 9,24 & 8,78 & 9,37 & 9,44 \\
Mais de 1/2 a 1 SM & 16,31 & 16,72 & 18,67 & 19,10 \\
Mais de 1 a 2 SMs & 24,82 & 27,48 & 27,50 & 29,10 \\
Mais de 2 a 3 SMs & 12,43 & 10,21 & 10,12 & 10,70 \\
Mais de 3 a 5 SMs & 9,78 & 10,47 & 9,08 & 7,62 \\
Mais de 5 a 10 SMs & 6,26 & 6,60 & 6,00 & 6,40 \\
Mais de 10 a 20 SMs & 2,91 & 2,82 & 2,32 & 2,25 \\
Mais de 20 SMs & 1,34 & 1,03 & 0,92 & 0,88 \\
Sem rendimento & 15,60 & 14,40 & 14,92 & 13,15 \\
Sem declaração & 1,31 & 1,49 & 1,10 & 1,36 \\
Total & 100,00 & 100,00 & 100,00 & 100,00 \\
\hline
\end{tabular}

Fonte: IBGE - Pesquisa Nacional por Amostra de Domicílios

Em 2005, os 10\% dos ocupados com os maiores rendimentos detinham $44,7 \%$ do total das remunerações de trabalho. Em 1995 esse percentual era de $47,1 \%$. Já entre os $10 \%$ com os menores rendimentos, a evolução foi de 1\% para 1,1\% entre 1995 e 2005, respectivamente. Em 2006, houve aumento em todas as classes de rendimentos, mas com expansão maior nos segmentos de mais baixa renda. O Gráfico 5, que apresenta o Índice de Gini da distribuição do rendimento mensal dos ocupados com 10 anos ou mais, indica uma tendência de melhora da distribuição da renda do trabalho.

Contudo, quando são contempladas rendas não originárias do trabalho, há indicações de que as famílias mais ricas tendem a se apropriar de maior parte da renda nacional. Essas indicações estão presentes no trabalho de Pochmann et al. (2004). Não está descartado, portanto, que em paralelo à melhora da distribuição do rendimento dos ocupados, ao aumento do rendimento dos ocupados com menores remunerações e à redução relativa dos com maiores rendimentos, esteja piorando a distribuição da renda nacional.

18 Segundo o IBGE, 1996 foi o ano em que o rendimento atingiu seu ponto máximo na década de 1990. 
MARQUES, R. \& MENDES, A. Sobre a política de combate à pobreza no governo Lula...

GRÁFICO 5- ÍNDICE DE GINI DA DISTRIBUIÇÃO DO RENDIMENTO MENSAL DE TODOS OS TRABALHOS DAS PESSOAS DE 10 ANOS OU MAIS DE IDADE, OCUPADAS NA SEMANA DE REFERÊNCIA, COM RENDIMENTO DE TRABALHO (BRASIL, 1995 - 2006)

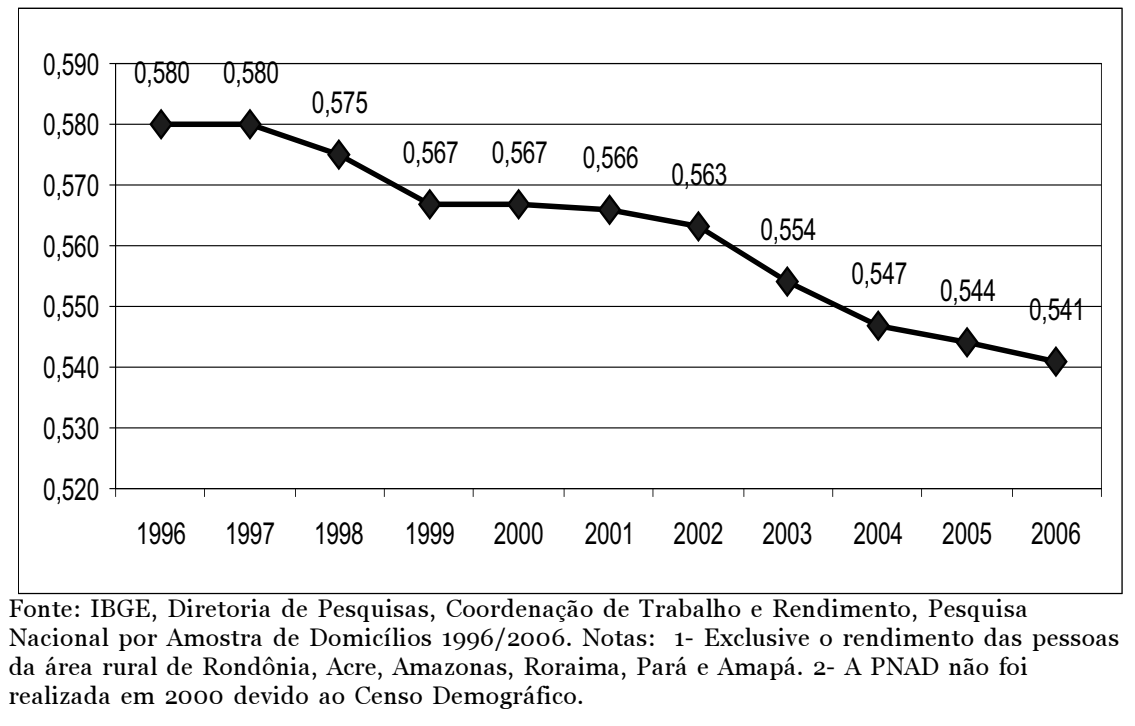

\section{Reflexões finais}

Não há dúvida de que o governo Lula, com a implantação em praticamente todos os municípios do Bolsa Família, provocou melhora nas condições de vida de milhões de brasileiros. Em outubro de 2006, esse programa beneficiava 11.009.341 famílias, ao custo de $\mathrm{R} \$ 680,08 \mathrm{mi}$ lhões no mês, alcançando, portanto, 48.441 .100 pessoas, isto é, $25,9 \%$ da população estimada pelo IBGE para 2006. Isso significa que parcela da população brasileira situada abaixo da linha de pobreza conseguiu ultrapassá-la, por meio do recebimento dessa transferência.

Mas as condições mínimas de acesso ao Bolsa Família exigem uma renda per capita inferior a R\$ 60,00, o que é, sem dúvida muito baixo. Se tomarmos como parâmetro o salário mínimo de R\$380,00 (vigente em 2007) como a renda de uma família de quatro membros (para ficarmos mais próximos do tamanho da família da região nordeste $(4,34$ membros) e da região norte $(4,01)$, regiões sabidamente as mais pobres do país, a renda per capita ficaria em $\mathrm{R} \$ 95,00$, o diferencial entre a renda per capita exigida para ter acesso ao Bolsa Família e a referenciada ao salário mínimo é de simplesmente R\$35,00. 
Isso significa que, mesmo sendo o Bolsa Família importante, posto que modifica as condições de vida de parcela importante do povo brasileiro, ele não está considerando sequer o parâmetro salário mínimo. Como sabido, o salário mínimo constitui um piso salarial legal, e qualquer pagamento abaixo dele é considerado imoral pela sociedade. Segundo sua legislação fundadora, o salário mínimo seria, ainda, um salário capaz de manter o trabalhador e sua família. Evidentemente que, mesmo levando em conta a recuperação observada nos últimos anos, seu valor real foi deteriorado ao longo das décadas que nos separam da adoção do primeiro salário mínimo no Brasil, de forma que hoje está longe de corresponder ao mínimo necessário para a sobrevivência de uma família de dois adultos e duas crianças, tal como escrito naquela legislação.

Assim, mesmo considerando que o salário mínimo perdeu o seu sentido primeiro, passando hoje a representar o piso legal nacional ${ }^{19}$, o fato de o Bolsa Família não o ter como referencial implica que essa política do governo Lula não leva em conta a necessidade de todos terem o direito de poder contar com igual renda mínima, no caso, de valor igual ao salário mínimo. O entendimento que o salário mínimo corresponderia à renda mínima necessária para alguém sobreviver decorre do fato óbvio que não há diferença entre as necessidades básicas de um assalariado e de um catador de caranguejos, por exemplo.

Talvez a diferença entre as condições de acesso do Bolsa Família e as do piso previdenciário e do valor do Benefício de Prestação Continuada (BPC) seja explicada pelo fato de esses últimos, que se constituem direitos, estarem fundamentados na idéia do trabalho. Tanto um como outro são, em última análise, um valor de base concedido a quem se retirou do mercado de trabalho, isto é, corresponde à cobertura do risco velhice. No caso dos beneficiários do Bolsa Família, essa "condição" não está explícita, pois trata-se de transferir renda à população extremamente pobre, com idade inferior a 65 anos, posto que se tivessem essa idade, poderiam requerer o BPC. Mas o Bolsa Família também tem como referencial o trabalho (ou a perda da capacidade laboral devido à idade), pois pressupõe a necessidade da família trabalhar para completar sua renda.

Caberia nos perguntarmos em que condições os beneficiários do Bolsa Família vão buscar essa complementação. Ao que parece, nas mesmas condições em que vinham fazendo antes, pois as determinações das rendas nos grotões do país e mesmo na periferia das grandes capitais não sofreram nenhuma alteração para melhor. A história da acumulação brasileira indica que ela contempla uma lógica perversa, de forma que, 
mesmo quando a economia cresce, se aprofundam as desigualdades e aumenta a pobreza absoluta.

Mudar esses determinantes é, portanto, um imperativo para quem afirma que deseja lutar contra a pobreza escandalosa que existe no país. O combate à pobreza não pode se resumir à transferência de renda, e ainda mais nas condições de acesso em que está fundamentada. Evidentemente que a transferência de renda para as famílias mais pobres deve ser vista como uma tarefa emergencial, que nenhum governo poderia se furtar de fazer. Mas combater a pobreza somente com o Bolsa Família, sem que esse programa esteja associado a outras políticas, pode resultar, inclusive, no aumento de seus "demandantes".

É por isso que não basta, também, para promover a inclusão social e diminuir o nível de desigualdade, que o governo estimule a geração de emprego e renda - o que dificilmente pode-se dizer que está fazendo, ao praticar elevadas taxas de juros e ao perseguir elevados superávits operacionais para pagar o serviço da dívida. Sem que seja promovida a reforma agrária e sem o enfrentamento dos demais fatores determinantes da concentração de renda e do patrimônio, o resultado será a manutenção eterna de políticas assistenciais, do tipo Bolsa Família.

No caso brasileiro, os pesquisadores da área de políticas sociais deveriam buscar uma denominação mais adequada para esse tipo de programa do que chamá-las simplesmente de "focalizadas" em oposição a "universal". Isso porque, tratando-se de mais de $25 \%$ da população, dificilmente se pode enquadrá-la como focalizada no sentido que sempre se usou esse termo. A dificuldade encontrada está no fato de exigir teste de meios, o que a caracterizaria como focalizada, mas que, ao mesmo tempo abrange parcela significativa dos brasileiros. O problema que se coloca deriva, portanto, do grau de desigualdade da sociedade brasileira, o que não estava presente quando foram forjados na literatura internacional os termos "focalizada" e "universal".

Ao mesmo tempo em que se fazem necessárias medidas que quebrem a lógica perversa da acumulação capitalista brasileira, é urgente a instituição, como um direito, da garantia de determinado nível de renda para todos. Já chamava a atenção o mestre Furtado (2002: 16) que, "para participar da distribuição de renda, a população necessita estar habilitada por um título de propriedade ou pela inserção qualificada no sistema produtivo." De forma contundente, para esse autor isso seria possível por meio de uma reforma patrimonial.

No que se refere à renda, ela precisa ser entendida como um direito derivado do conceito de cidadania, portanto garantida pela constituição brasileira. Dessa forma, essa renda mínima, no espírito original do projeto do senador Eduardo Suplicy, não comporia uma política 
assistencial e sim faria parte dos direitos "básicos" de qualquer cidadão brasileiro, tal como é compreendido o acesso aos cuidados com a saúde e o ensino fundamental.

A garantia dessa renda não teria como propósito substituir o sistema de proteção social atualmente existente, mas, ao reconhecer a complexidade da realidade brasileira, de complementar o sistema atual. Não seriam necessários muitos recursos para diminuir o número de famílias localizadas abaixo da linha de pobreza. Mas mesmo que um programa mais ambicioso (que se preocupe em garantir uma qualidade de vida mais elevada, e não somente permitir que as famílias pobres ultrapassem essa linha) envolvesse uma quantidade de recursos mais significativa, essa deveria ser a prioridade em termos de política social imediata, pois somente dessa maneira pode-se dizer que a sociedade brasileira estaria verdadeiramente comprometida com o desenvolvimento do país. Crescer sem distribuir a renda é não só reproduzir o passado de desigualdades, como aprofundá-lo. Essas foram sempre as palavras do mestre Furtado, deixando entre nós a idéia-síntese: "o desenvolvimento verdadeiro só existe quando a população em seu conjunto é beneficiada" (Furtado 2002: 21).

Para a sustentação dessa política, no entanto, seria necessário que o Estado brasileiro recuperasse sua capacidade de intervenção, o que exigiria rediscutir as conseqüências do enorme esforço que tem sido feito nos últimos anos para promover o superávit primário. Seria necessário, ainda, que o sistema tributário fosse bastante alterado, de maneira a promover as bases para uma redistribuição de renda, angariando recursos para a promoção dessa e de outras políticas, consideradas essenciais pela sociedade brasileira.

Existe uma relação estreita entre pobreza e concentração de poder. É dessa compreensão que decorre o entendimento que, no caso do Brasil, onde milhões de pessoas vivem abaixo da linha da pobreza, os benefícios atualmente assistenciais, que promovam redistribuição de renda, devem superar o assistencialismo e constituírem parte dos direitos básicos ou fundamentais de qualquer brasileiro. Essa mudança de status, além de garantir a continuidade dos programas, retira do assistencialismo seu caráter de moeda política, o que faz aumentar a força dos poderosos entre os segmentos mais carentes da população.

Tal proposição, no entanto, como já mencionado anteriormente, implica mudanças que se relacionam à ordem econômica e política do país. Alterar o quadro estrutural brasileiro (que reproduz sem parar os determinantes da pobreza) significa enfrentar os interesses dos beneficiários do processo que historicamente cria e recria a pobreza e a desigualdade. O Programa das Nações Unidas para o Desenvolvimento 
MARQUES, R. \& MENDES, A. Sobre a política de combate à pobreza no governo Lula...

(PNUD), na apresentação do Relatório do Desenvolvimento Humano 2004, está correto ao dizer que (PNUD 2005: V.):

A menos que as pessoas pobres e marginalizadas - que na maioria das vezes são membros de minorias religiosas, étnicas, ou migrantes possam influenciar ações políticas, a nível local e nacional, não é provável que obtenham acesso eqüitativo ao emprego, escolas, hospitais, justiça, segurança e outros serviços básicos.

Mas dificilmente pode-se afirmar que a democracia formal é suficiente para garantir o acesso aos benefícios, ações e serviços que compõem a proteção social, a educação, entre outros aspectos a que deveriam ter direito qualquer pessoa. Isso porque, para a população mais pobre, não falta somente a base material para levar uma vida digna, mas a consciência ativa, portanto, a capacidade de fazer valer os direitos que uma democracia formal garante em suas leis. No Brasil, há inúmeros exemplos dessa realidade: desde o salário mínimo não cumprido em grotões do país, até a dificuldade de acesso a informações que expliquem o caminho burocrático a ser percorrido para, ao final, garantir um benefício.

Desnecessário dizer que a adoção de uma renda mínima, que dificilmente poderia ser de valor diferente do que se entende por um salário mínimo, exigiria a redefinição do mínimo a ser pago ao trabalhador ativo. $\mathrm{O}$ pretenso conflito entre o direito à renda mínima e o desejo de trabalhar seria resolvido pela elevação do piso salarial e, quem sabe, pela redução da desigualdade existente no país.

\section{Referências}

BALTAR, P. (2005) "Salário Mínimo e Mercado de Trabalho". Texto para o Seminário Salário Mínimo e Desenvolvimento. Unicamp, Campinas.

BARROS, R. \& HENRIQUES, R \& MENDONÇA, R. (2000). “A Estabilidade inaceitável: Desigualdade e Pobreza no Brasil”. Textos para Discussão 800. Instituto de Economia Aplicada, Rio de Janeiro.

BRANT, R. (2001). Desenvolvimento Social, Previdência e Pobreza no Brasil. Conjuntura SOCIAL - A previdência Social Reavaliada no I, 12(2), Brasília, MPAS.

BELTRÃO, K \& CAMARANO, A. \& LEITÃO E MELlO, J. (2005). “Mudanças nas Condições de vida dos Idosos Rurais Brasileiros: Resultados nãoesperados dos Avanços da Seguridade Rural.” Textos para Discussão 1066. Instituto de Pesquisa Econômica Aplicada, Rio de Janeiro.

DRAIBE, Sônia (1989) “A especificidade do Welfare State brasileiro". In: 
MPAS/Cepal. A política social em tempo de crise: articulação institucional e des-centralização, vol. 3. Brasília.

DELGADO, G. \& CASTRO, J. A. (2004). "Direitos Sociais no Brasil sob Risco de Desconstrução". Políticas Sociais - Acompanhamento e análise $\mathbf{n}^{\circ}$ 9, nov. Instituto de Pesquisa Econômica Aplicada, Brasília.

FURTADO, C. (2002). Em busca de novo modelo: reflexões sobre a crise contemporânea. São Paulo: Paz e Terra.

INSTITUTO BRASILEIRO DE ECONOMIA - FGV. URL: http:// www.ibre.fgv.br. Acesso em 29 de julho de 2004.

INSTITUTO BRASILEIRO DE GEOGRAFIA E ESTATÍSTICA. Pesquisa Nacional por Amostra de Domicílios (PNAD-2003, 2004, 2005 e 2006). URL: http:// www.ibge.gov.br. Acesso em 15 de outubro de 2007.

MARQUES, R. M. (1997) A proteção social e o mundo do trabalho. Bienal, São Paulo.

MARQUES, R. M. \& MENDES, Á. (2005). “Crescimento, Desenvolvimento e Cidadania." Indicadores Econômicos FEE 33(1):293-316.

MARQUES, R. M. \& MENDES, Á. \& GUEDES, M. \& HUTZ, A (2004). "A importância do Bolsa Família nos municípios brasileiros, relatório de pesquisa." Ministério do Desenvolvimento Social e Combate à Fome MDS, Brasília.

MARQUES, R. M. \& MENDES, Á. \& GUEDES, M. \& JANSEN, M. (2006). "O Bolsa família e o BPC: cobertura e importância nos municípios, relatório de pesquisa." Ministério do Desenvolvimento Social e Combate à Fome, Brasília.

MINISTÉRIO DA PREVIDÊNCIA E DA ASSISTÊNCIA SOCIAL - MPAS. Boletim Estatístico da Previdência Social. Brasília. URL: http://www.mpas.gov.br. Acesso em 24 de junho de 2007.

MINISTÉRIO DA PREVIDÊNCIA E DA ASSISTÊNCIA SOCIAL - MPAS (2006). "Evolução recente da proteção social e seus impactos sobre o nível da pobreza." Informe da Previdência Social 18 (3). MPAS, Brasília. URL: http:/ /www.mpas.gov.br. Acesso em 24 de junho de 2007.

MINISTÉRIO DA SAÚDE (2003). Avaliação do Programa Bolsa Alimentação Estudo 2: Análise de Impacto Preliminar. Ministério da Saúde, Brasília.

POCHMANN, M. \& CAMPOS, A. \& BARBOSA, A. (2004) "Atlas da Exclusão Social, volume 3: Os Ricos no Brasil”. São Paulo: Cortez.

PROGRAMA DAS NAÇÕES UNIDAS PARA O DESENVOLVIMENTO (2004). Relatório para o Desenvolvimento Humano 2004. URL: http:// www.pnud.org.br/rdh. Acesso em 15 de março de 2005.

Recebido em: 23 de outubro de 2007 Primeira resposta em: 22 de janeiro de 2008 Aceite em: 19 de fevereiro de 2008 